\title{
PENGARUH LAYANAN INFORMASI TERHADAP PENGETAHUAN SEKSUAL SISWA KELAS IPS 1 SMA NEGERI 6 BINJAI
}

\author{
Haposan Lumbantoruan \\ Email: posantoruan726@gmail.com
}

Pelita Bangsa Binjai

\begin{abstract}
Abstrak
Penelitian bertujuan untuk mengetahui pengaruh layanan informasi terhadap pengetahuan seksual siswa remaja di SMA Negeri 6 Binjai.Berdasarkan kajian teori terdapat perbedaan pengaruh tentang seksual pada saat sebelum dan sesudah diberikan layanan informasi pada siswa kelas IPS 1 SMA Negeri 6 Binjai Tahun Ajaran 2010 / 2011".Penelitian yang digunakan adalah kuantitatif, tehnik Analisis Varians 1 Jalur, yakni pre test dan post test. Siswa yang tidak diberikan pre testdiberikan kode A1 dan yang diberi pos test diberi kode A2. Sedangkan variable yang akan diukur atau variable terikatnya adalah pengetahuan seksual.Sampelnya 127 orang, hasil Analisis Varians 1 Jalur, maka diperoleh hasil sebagai berikut : a)Terdapat perbedaan pengetahuan seksual yang sangat signifikan antar siswa sebelum dan sesudah diberikan layanan informasi tentang seksual dengan Anava $\mathrm{F}=$ 117,914 dengan koefisien signifikan 0,000 artinya nilai signifikan yang diperoleh lebih kecil dari 0,010. Ada perbedaan pengetahuan seksual antar siswa sebelum dan sesudah diberikan layanan informasi tentang seksual, diterima.b)Diketahui bahwa setelah diberi layanan informasi tentang seksual memiliki pengetahuan seksual yang lebih tinggi dengan nilai rata-rata 144,688 dibandingkan dengan sebelum diberikan layanan informasi tentang seksual dengan nilai rata-rata 109,288. Ini berarti layanan informasi yang dilakukan peneliti memberikan pengaruh yang sangat berarti bagi remaja dalam memahami segala hal yang berkaitan dengan seksual. c)Bahwa para siswa SMA Negeri 6 Binjai , yang sedang duduk di tahun ajaran 2010 / 2011 memiliki pengetahuan seksual pada kategori tinggi, sebab mean empiric $(128,9889)$ selisihnya dengan nilai rata-rata hipotetik (110) melebihi nilai SD yakni 23,521.
\end{abstract}

Kata kunci: Layanan Informasi, Pengetahuan Seksual

\begin{abstract}
This study aims to determine the effect of information services on the sexual knowledge of adolescent students at State High School 6 Binjai. Based on the theoretical study, there are differences in the influence of sexual relations before and after being given information services to students in Social Studies class 1 State High School 6 Binjai in the 2010/2011 academic year. Students who were not given the pre-test were given the code Al and those who were given the post-test were given the code A2. While the variable to be measured or the dependent variable is sexual knowledge. The sample is 127 people, the results of the Analysis of Variance 1 Path, the following results are obtained: a) There is a very significant difference in sexual knowledge between students before and after being given information services about sexuality with Anova $F=117.914$ with a significant coefficient of 0.000, meaning that the significant value obtained is less than 0.010. There are differences in sexual
\end{abstract}


knowledge between students before and after being given sexual information services, received. b) It is known that after being given sexual information services, they have higher sexual knowledge with an average score of 144,688 compared to before being given sexual information services with an average value of 109.288. This means that the information services provided by the researcher have a very significant influence on adolescents in understanding all matters relating to sexuality. c) That the students of State High School 6 Binjai, who are currently sitting in the 2010/2011 academic year have sexual knowledge in the high category, because the empirical mean (128.9889) is different from the hypothetical average value (110) exceeding the SD score of 23,521.

\section{Keywords: Information Services, Sexual Knowledge}

\section{PENGANTAR}

Pada era globalisasi saat ini, pembangunan di Indonesia berkembang dengan sangat pesat.Hal ini di tandai dengan dibangunnya berbagai sarana Pendidikan pembelajaran dan sarana hiburan yang serba modern.Cepatnya kemajuan ini tidak terlepas dari kemajuan sarana informasi sebagai penunjang kemajuan ilmu pengetahuan dan teknologi.Perubahan-perubahan teknologi dan modernisasi dalam berbagai sekor yang berhubungan dengan kehidupan manusia demikian pesat sehingga mempengaruhi keseimbangan dan keserasian baik dalam kehidupan pribadi, keluarga maupun masyarakat, tidak terkecuali remaja.Rangsangan dari berbagai perubahan dan kemajuan ini dapat terlihat dalam kehidupan remaja di sekitar kita.

Kehidupan remaja yang unik sungguh menarik.Banyak hal tak terduga dari remaja mencuat kepermukaan.Kesempatan memperoleh Pendidikan dan meningkatkan teknologi informasi lebih banyak bahi mereka terutama tentang seks yang amat menarik minat remaja untuk mencari tahu. Sayangnya disamping manfaat positif dari semua itu, pengaruh negatifnya lebih cepat diserap kaum remaja daripada yang baiknya.Demikian pula halnya dengan siswa-siswi di SMA Negeri 6 Binjai sebagai remaja yang sedang berkembang tanpa meraka sadari telah terpengaruh dengan budaya modern. Apalagi aktivitas dan praktek siswa-siswi tersebut sedikit banyaknya berhubungan langsung dengan dunia asing yang semakin maju dengan pesat dengan atas dasr tuntutan ini mereka yang tidak mampu dalam mengontrol diri akan mudah terjerumus dengan pengaruh tersebut.

Selain itu pergaulan yang bebas diantara para remaja tersebut terutama di luar batas pengetahuan sekolah sudah sangat sulit dikendalikan. Banyaknya siswa-siswi yang bergonta ganti pasangan dan banyakanya penampilan pornigrafi semakin menyala dan menyentuh berbagai media massa seperti koran, majalah, tabloid, flim. Buku dan gambar (foto) yang memperlihatan aura bahkan dalam tulisan, sandiwara, lawak, atau adegan murahan yang disenangi masyarakat dan lain sebagainya.Seiring perkembangan yang terjadi sudah saatnya pemberian penerangan dan pengetahuan masalah seksualitas pada remaja ditingkatkan. Pandangan besar masyarakat yang menganggap seksulitas merupakan suatu hal yang alamiah, yang nantinya akan diketahui dengan sendiriny setelah mereka menikah sehingga dianggap suatu hal yang tabu untuk dibicarakan secara terbuka, nampaknya secra perlahan-lahan harus diubah. Sudah saatnya pandangan seperti ini harus diluruskan agar tidak terjadi hal- 
hal yang tidak diinginkan dan membahayakan bagi anak dan remaja sebgai generasi penerus bangsa.Remja yang hamil diluar nikah, aborsi, penyakitkelamin dan lain-lain adalah contoh dari beberapa pahit yang sering terjaadi pada remaja sebgai akibat pemahaman yang keliru mengenai seksualitas.

Oleh sebab itu sangat diharapkan, relasi pada remaja sebgai seorang pelajar agar mereka dapat mengembangkan diri mereka kearah yang lebih sehat dan positif dan menjauhkan diri sertaa menolak untuk berprilaku dan bersikap melnggar normanorma yang ada dimasyarakat, terutama pada seks bebas sehungga mereka dapat mengenali kemampuan yang ada pada dasarnya dan dapat mengeskpresikannya kedalam prilaku dan suskses dalam bidnag akademik dimasyarakat karena hal inilah yang diharapkan juaga pada lingkungannya. Oleh yang demikian, berbekalan minat dan keprihatinan penulis terhadap permaslahan social remaja masa kini maka penulis tertarik untuk mengangkat permasalah sebagai kajian dengan judul "Pengaruh pemberian layanan informasi terhadap pengetahuan seksual siswa kelas IPS 1 SMA Negeri 6 Binjai Tahun Pelajaran 2010/2011".

Berdasarkan hal diatas, maka yang terjadi perumusan maslah dalam penelitian ini adalah : 1. Bagaimana pengetahuan seksual di SMA Negeri 6 Binjai? 2.Apakah pengaruh layanan informasi terhadap pengetahuan seks di SMA Negeri 6 Binjai?

\section{Kerangka Berpikir}

Sebagai dampak dari adanya suatu larangan atau tabu dalam membicarakan seks. Remaja berusaha mencari segala sesuatu yang berhungan dengan seks.Informasi yang mereka peroleh menjadi pengetahuan tentang seks bagi mereka.Pengetahuan yang mereka peroleh dari berbagai sumber tersebut dapat berupa, pengetahuan tentang pacaran, pengetahuan tentang alat kelamin, pengetahuan tentang mitos seputar seksual, pengetahuan tentang penyakit meular seksual, pengetahuan mengenai pacaran, dan pengetahuan tentang seks menyimpang.

Jadi, pengetahuan seksual adalah segala sesuatu yang diketahui oleh remaja yang berkenaan dengan masalah seksual.Pengetahuan seks ini menjadi dasar bagi mereka untuk melakukan aktivitas seksual (perilaku seksual). Perilaku seksual yang biasa dilakukan oleh remaja dapat berupa dua bentuk aktvitas, yaitu: a) Aktivitas yang dilakukan dengan orang lain, aktivitas ini dapat berupa aktivitas seksual awal, seperti : berpegangan tangan, bercium (cium bibir / cium pipi), memeluk bahu, memeluk pinggang, mencium bibir sambil berpelukan, meraba alat kelamin, mencium daerah erogen, aktivitas seks lanjutan seperti petting dan intercourse. b) Aktivitas yang dilakukan sendiri, antara lain: onani atau masturbasi, berfantasi seksual.

Ada beberapa kecenderungan yang dilakukan oleh remaja saat dia memperoleh informasi tentang seksual, yaitu langsung memperaktekkan informasi yang mereka peroleh walaupun mereka tidak tahu baik atau buruk tindakan mereka.

\section{METODE PENELITIAN}

Jenis atau metode penelitian yang digunakan dalam penelitian ini adalah metode eksperimen yang mencakup studi tentang fenomena sebagaimana adanya dan melakukan kajian hubungan antara beberapa variable yang terkait dengan variable yang diteliti.Jenis data dalam penelitian ini termasuk data kuantitatif. Subjek penelitian ini adalah siswa kelas IPS SMA Negeri 6 Binjai, T.A 2020 / 2011 dan sampel yang diambil kelas IPS 1 yang berjumlah 45 orang siswa . 
Disain yang akan digunakan dalam penelitian ini menggunakan disain pre-test dan post-test. Di dalam disain ini observasi dilakukan sebanyak dua kali yaitu sebelum eksperimen dan sesudah eksperimen.

Pelaku dalam penelitian adalah peneliti. Kegiatan yang akan peneliti lakukan adalah: a. melakukan pre-test dengan cara membagikan angket tentang pengetahuan seksual kepada siswa. b. melakukan layanan informasi sebanyak 4 kali pertemuan dengan topic yang berhubungan dengan pengetahuan seksual. c. Melakukan pro-test dengan membagikan angket kembali.

Dalam penelitian ini tehnik pengumpulan data menggunakan metode angket (questioner) dan instrument yang digunakan adalah angket-angket (questioner). Angket adalah kumpulan dari pertanyaan yang diajukan kepada responden, secara tertulis, dan cara menjawabnya juga dilakukan dengan tertulis juga. Setiap responden akan menerima angket yang akan diisi, kemudian jawaban yang sama dengan nilai skor akan dikelola dan dianalisis sesuai dengan data yang akan diperoleh. Dalam memberikan jawaban, siswa hanya member tanda check list pada kolom atau tempat yang sudah disediakan.

\section{HASIL DAN PEMBAHASAN}

Penelitian ini menggunakansisti one way design, artinya penelitian ini dilakukan 2 kali pada orang yang sama. Pada tahap awal, penelitian dilakukan dengan cara menyebarkan angket pengetahuan seksual kepada 45 orsng siswa. Setelah selesai peneliti melakukan penelitian, kembali pada waktu yang lain pada orang yang sama, namun sebelum angket kembali digunakan peneliti terlebih dahulu melakukan atau memberikan informasi tentang pengetahuan seksual sebanyak 4 kali pertemuan. Keseluruhan pertemuan tersebut berkaitan dengan perilaku seksual.Setelah 4 kali pertemuan selesai dilakukan, peneliti pada waktu berikutnya menyebarkan skala pengetahuan seksual. Setelah dilakukan penyebaran angket, maka langkah selanjutnya melakukan memisahkan berkas berdasarkan waktu pelaksanaannya, yakni sebelum dilakukan layanan informasi tentang pengetahuan seksual.Kemudian melakukan scoring atas jawaban angket tersebut.

Langkah berikutnya adalah menghitung nilai total masing-masing siswa sebelum dan sesudah diberikan layanan informasi.Inilah yang menjadi data induk penelitian, dimana sebagai variable bebasnya $(\mathrm{X})$ adalah pemberian layanan informasi tentang seksual dan sebagai variable terikatnya $(\mathrm{Y})$ adalah pengetahuan atau seksual.

\section{Data Pengetahuan Analisis Anak}

a. Nilai rata-rata / Mean Hipotetik

Jumlah butir pernyataan yang dipakai dalam mengungkap pengetahuan seksual adalah sebanyak 44 butir yang diformat dengan skala linkert dalam 4 pilihan jawaban, maka nilai rata-rata hipotetiknya adalah : $(44 \mathrm{X} 1)+(44 \mathrm{X} 4): 2=$ 10.

b. Nilai rata-rata / Mean Empirik

Berdasarkan analisi data, diketahui bahwa, mean empiric variable pengetahuan seksual adalah 128,9889.

c. Kriteria

Dalam upaya mengetahui pengetahuan seksual para siswa, maka perlu dibandingkan antara mean / nilairata-rata empiric dengan mean / nilai rata-rata 
hipotetikdengan memperhatikan besarnya bilangan SD dari variable yang sedang diukur. Jadi, dalam hal ini variable pengetahuan seksual nilai SD adalah 23,521.

Dari besarnya bilangan SD tersebut, maka mean / nilai rata-rata hipotetik < mean / nilai rata-rata empiric, dimana selisih melebihi 23,521, maka dinyatakan bahwa pengetahuan seksual siswa dinyatakan tinggi dan apabila mean / nilai rata-rata hipotetik > mean / nilai rata-rata empiric, dimana selisih melebihi 23.521, maka dinyatakan bahwa pengetahuan siswa rendah. Apabila nilai / mean rata-rata empiric dengan mean hipotetik tidak berselisih apabila melebihi 23,521, maka pengetahuan seksual siswa dinyatakan sedang.

Table 1. Hasil Perhitungan Nilai Rata-rata Hipotetikdan Nilai Rata-rata Empirik

\begin{tabular}{|c|c|c|c|c|}
\hline \multirow{2}{*}{ Variabel } & \multirow{2}{*}{ SD } & \multicolumn{2}{|c|}{ Nilai Rata-rata } & \multirow{2}{*}{ Keterangan } \\
\hline & & Hipotetik & Empirik & \\
\hline $\begin{array}{l}\text { Pengetahuan } \\
\text { Seksual }\end{array}$ & 23,512 & 110 & 126,9889 & $\begin{array}{c}\text { Pengetahuan Seksual tergolong } \\
\text { sedang }\end{array}$ \\
\hline
\end{tabular}

Berdasarkan perbandingan kedua nilai rata-rata di atas (mean hipotetik dan mean empiric), maka dapat dinyatakan bahwa pengetahuan seksual siswa berada pada kategori tinggi, sebab mean empiric ( 126,9889) selisihnya dengan rata-rata hipotetik ( 110 ) melebihi bilangan SD yakni 23,521. Kondisi Pengetahuan Seksual Siswa Kelas X SMA Negeri 6 Binjai.

Selanjutnya dari kurva di atas dapat dibuat table yang menggambarkan persentase dan frekkuensi siswa mengenai pengetahuan seksual.

Table 2. Penggolongan Interval Pengetahuan Seksual Siswa

\begin{tabular}{|c|c|c|c|}
\hline Skor & Kategori & Frekuensi & Persen (\%) \\
\hline$<62,958$ & Sangat Rendah & 0 & $0 \%$ \\
\hline $62,959-86,479$ & Rendah & 0 & $0 \%$ \\
\hline $86,480-133,521$ & Sedang & 10 & $22,222 \%$ \\
\hline $133,521-157-042$ & Tinggi & 27 & 60 \\
\hline$>157,043$ & Sangat Tinggi & 8 & $17,777 \%$ \\
\hline \multicolumn{2}{|c|}{ Jumlah } & 45 & $100 \%$ \\
\hline
\end{tabular}

Metode analisa data yang digunakan untuk melihat apakah ada perbedaan pengetahuan seksual antara siswa sebelum diberi pelayanan tentang seskaual dan sesudah diberi pelayanan informasi tentang seksual, maka digunakan rumus Analisis Varian 1 Jalur.

Namun sebelum data dianalisis dengan tehnik Analisis Varian 1 Jalur, terlebih dahulu dilakukan uji asumsi terhadap variable yang menjadi pusat perhatian, yaitu data variable layanan informasi seksual ddan seksual, yang meliputi uji normalitas sebaran dan uji homogenitas varians.

\section{KESIMPULAN}

Berdasarkan hasil yang telah diperoleh dalam penelitian ini, maka dapat disimpulkan hal-hal sebagai berikut :

1. Terdapat perbedaan pengetahuan seksual yang sangat signifikan antar yang sebelum dan sesudah diberikan layanan informasi tentang seksual. Hasil ini di ketahui dengan melihat nilai dan koefisien perbedaan Anava $F=117,914$ 
dengan koefisien signifikansi 0,010, dengan demikian maka hipotesi yang diajukan yang berbunyi ada perbedaan pengetahuan seksual antar siswa sebelum dan sesudah diberikan layanan informasi tentang seksual, diterima.

2. Diketahui bahwa setelah diberikan layanan informasi tentang seksual memilikipengetahuan seksual yang lebih tinggi dengan nilai rata-rata 144,688 dibanding dengan sebelum diberikan informasi tentang seksual dengan nilai rata-rata 109,288. Ini berarti bagi remaja dalam memahami segala hal yang berkaitan dengan seksual.

3. Bahwa para siswa SMA Negeri 6 Binjai, yang sedang duduk di tahun ajaran 2010 /2011 memiliki pengetahuan seksual pada kategori tinggi, sebab mean empiric $(128,9889)$ selisihnya dengan nilai rata-rata hipotetik (110) melebihi bilangan SD yakni 23,521.

\section{DAFTAR PUSTAKA}

Agus Irianti. 2007. Statistik jilid 4. Prenada Media Group.

Akurinto, Suharsimi. 2002. Prosedur Penelitian Suatu Pendekatan Praktis. Jakarta : Rineka Cipta.

Dahlani, Ifdil. 2008. Layanan Informasi http://one.indoskripsi.com/click.com.diakses 5 Februari 2010.

Dinawati, Ajen. 2003. Pendidikan seks Bagi Remaja. Jakarta : Pustaka Kawan.

Hadi, Sutrisno. 2004. Statistic jilid 1 Yokyakarta : Penerbit Andi.

Hurlock E.B. 202. Psikilogi Perkembangan . Bandung. Erlangga.

Kadir, Abdul. 2003. Pengertian Informasi http://www.blog.re.or.id Diakses 20 Februari 2010.

Lamudin. 2006. Konsep-konsep Dasar Bimbingan Konseling. Bandung: Citapustaka Media.

Masri.2000. Metode Penelitian Survei. Jakarta. Matahari, Bakti.

Muta'din, Zainun. 2002. Pendidikan Seksual Pada Remaja. Jakarta.

Pratiwi.2004. Pendidikan Seks Untuk remaja.Yokyakarta. Tugu Publisher.

Prayitni dan Ami Erman. 2004. Dasar-dasar Bimbingan konseling. Jakarta: Rineka Cipta.

Prayitno. 2004. Seri Layanan Konseling. Padang. Universitas Negeri Padang.

Sudrajat, Ahmad. 2008. Jenis-jenis Layanan Bimbingan dan Konseling. Dalam http://Akhsudrajat.Wordpress.com.

Sumadi, Suryabrata, 1997. Metodelogi Penelitian. Jakarta: Raja Grafindo Persada 